scientists who are specially interested in tropical soils from the above-mentioned points of view, not only from the Caribbean, but also from other countries; special reference was made to Cuba, Haiti and the Dominican Republic, and it was recommended that the Governments of these countries should be invited to send representatives to participate in the conference. The recommendations have been approved by the Caribbean Commission, and a working committee has been set up to prepare for the conference, the date of which has not yet been definitely fixed.

\section{The Giant Panda}

IT has been announced by the Chinese Government that the Szechwan Frovincial Government has limited the catching of pandas to one pair every five years. This regulation was made at the request of the Academia Sinica with the view of protecting this rare species from extinction. Few mammals have caused more scientific and lay interest than the giant panda (Ailuropoda melanoleuca, David), first made known to science when David sent skins home to France from his travels in western China during 1868-69. Several expeditions attempted to secure live specimens, and in 1937 one was exhibited by the New York Zoological Society, and in the following year another was shown in London. Their similarity to the true bears is not borne out by the skull, which resembles the raccoons, and thus the sub-family Ailurinæ of the raccoons (Procyonidæ) was created for the giant panda and the more numerous lesser panda (Ailurus fulgens). It is to be hoped that the lead by the Chinese Government will encourage other Eastern States to eurb the activities of collectors, who are likely to exterminate animals of limited distribution.

\section{Education and Training of Laboratory Technicians}

A Committee on the Education and Training of Laboratory Technicians was set up by a conference convened in 1946 by the Association of Scientifie Workers, the Association of University Teachers and the British Association of Chemists. Among the bodies now represented on it are the Institute of Physics, the Royal Institute of Chemistry, the Biological Council, the Institute of Medical Laboratory Technology and the Science Masters' Association, in addition to the three Associations that convened the conference; there are also representatives of industry and a number of senjor laboratory technicians on the Committee; representatives of other organisations concerned with the problem, including the Ministry of Education, are being coopted. The chairman of the Committee is Prof. F. R. Winton and the honorary secretary is now Dr. H. J.T. Ellingham (secretary, Royal Institute of Chemistry). The attention of the Committee has been directed essentially to that important class of technicians, which includes laboratory stewards and, at the highest level, laboratory superintendents, whose work is vital to the maintenance and operation of research laboratories in industrial organisations, research associations and academic institutions and of laboratories for the instruction of students in universities, technical colleges and schools. Their work involves experience of techniques derived from a number of branches of science and technology; most of them are to be regarded not-as potential chemists, physicists, biologists, otc., but as potential first-class laboratory technicians. So far, however, few courses have been provided for the training of technicians of this type, nor is there any qualification in their own field to which they may aspire. The Committee is therefore engaged in preparing syllabuses for the certificate and diploma stages of a general course of training for such laboratory technicians, based on proposals put forward by a sub-committee consisting of the laboratory technician members of the Committee. It is hoped to start a trial course early in 1948. In the meantime, it is understood that a representative group of laboratory technicians who have been associated with the work of the Committee are taking steps to constitute a professional qualifying body similar in many respects to the Institute of Medical Laboratory Technology.

\section{Thermo-nuclear Reactions under Terrestrial Con- ditions}

The possibility of initiating thermo-nuclear re. actions under terrestrial conditions is discussed by Dr. J. H. J. Poole (Proc. Roy. Dublin Soc., 24, 71; 1946). It is pointed out that the results obtained by Atkinson, Gamow and Teller, Bethe and others, in their investigations of thermo-nuclear reactions as applied to stellar conditions, are equally valid for terrestrial conditions. In applying these results to the sea, which is the largest known source of thermonuclear energy on the earth, four types of reactions need to be considered. They are proton-proton, proton-deuteron, and two forms of deuteron-deuteron reaction. The deuteron-deuteron reaction is shown to be the most important, by comparing the values of the rate of generation of thermo-nuclear energy derived for the several reactions. The question whether it is possible to initiate and maintain a thermo-nuclear reaction in the sea is discussed by considering the case of a sphere of water in which thermo-nuclear energy is being generated and which is radiating as a black-body. It is shown that the minimum radius of such a sphere must be of the order of $3 \times 10^{6} \mathrm{~km}$., so that there would seem to be very little danger of starting a world-wide explosion by dropping an atom bomb into the sea. (Dr. Poole's paper was written prior to the Bikini atom bomb tests.) If the sphere consisted entirely of heavy water, the minimum radius is reduced to $3.6 \mathrm{~km}$., so that even in this extreme case a selfmaintained thermo-nuclear explosion would be unlikely to be started by an atom bomb. It is probable, however, that if heavy water were incorporated in the bomb, with some of the energy liberated in the explosion being derived from deuteron reactions, more complete fission of the active heavy-element constituent would be ensured by the neutrons emitted by the reaction.

\section{Catalogue of Laboratory Equipment}

IN the days before the War, the comprehensive catalogues of the laboratory furnishing firms were the 'bibles' of all those concerned with the ordering and purchasing of laboratory apparatus and instruments. The long years of abnormal circumstances and particularly of paper shortages have deprived laboratory workers of these ready and compact sources of information covering the whole range of scientific laboratory equipment. It is therefore heartening as a foretaste of more normal conditions that Messrs. Griffin and Tatlock, Ltd., have been able to issue a new and very substantial catalogue of scientific apparatus, and that the familiar, but out-of- 